\title{
Thermal Analysis of an Installation Fault Concerning a Ripple Control Transformer
}

by Vassilios Chatziathanasiou, Georgios T. Andreou, Olga Gkaitatzi, Ozlem Otuzbir, and Dimitrios P. Labridis

Aristotle University of Thessaloniki, Thessaloniki, Greece

\section{Abstract}

The Greek Public Power Company utilizes Ripple Control by the use of three single phase infusion current transformers. Recently a problem occurred in one of the transformers, when its feeding cable blew. The cable was replaced with a new one, which again blew after some time. This paper deals with the analysis of the reasons that led to this problem. A theoretical study is presented, along with an infrared thermography depiction of the problematic transformer. Finally, thermal analysis is also used on an experimental setup for the better comprehension of the incident.

\section{Keywords}

Infrared Thermography, Ripple Control Transformer, Thermal Analysis

\section{Introduction}

In many Greek cities, Ripple Control is used for the performance of certain services by the Public Power Company (PPC). These services include the transition of Low Voltage (LV) customers to reduced tariffs during the night, as well as the management of public lighting. The Ripple Control is realised with the usage of a 20-60 $\mathrm{kW}$ signal transmitter, which operates at a voltage of $1000 \mathrm{~V}$ and sends a series of pulses at a frequency of 175$1600 \mathrm{~Hz}$, designating specific commands. The transmitters are connected via a current transformer to the Medium Voltage (MV) power distribution network of $20 \mathrm{kV}$, and the signal is thus spread until it reaches its final destination. The customers using Ripple Control services have respective receivers that are programmed to activate responding to the specific commands.

In a typical Ripple Control installation, the signal produced by the transmitter is injected in the 3-phase MV power distribution network via three single phase infusion current transformers with a total 3-phase rated power of $25 \mathrm{MW}$. Each transformer is connected to the MV power grid via a $150 \mathrm{~mm}^{2}$ copper cable with a maximum permissible thermal current of $442 \mathrm{~A}$. Recently a problem occurred in one of the Ripple Control systems of PPC. More specifically, the problem occurred in one of the infusion current transformers, when its feeding cable blew. The cable was replaced with a new one, which again blew after some time. The cable was replaced again, and thermal imaging was used to monitor its function. The thermal imaging results are shown in Fig. 1 and Fig. 2. More specifically, Fig. 1 depicts the thermal image of the Ripple Control Panel, whereas Fig. 2 shows the cable terminations on the infusion current transformers.

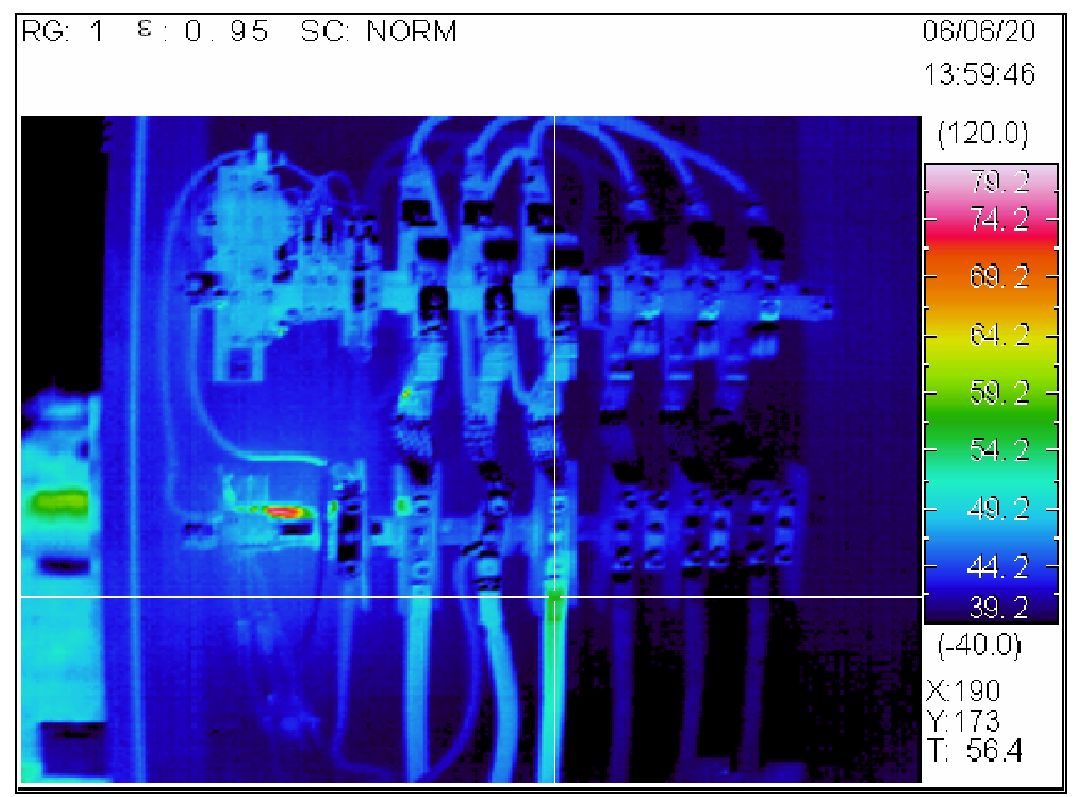

Fig. 1. Thermal image of Ripple Control Panel 


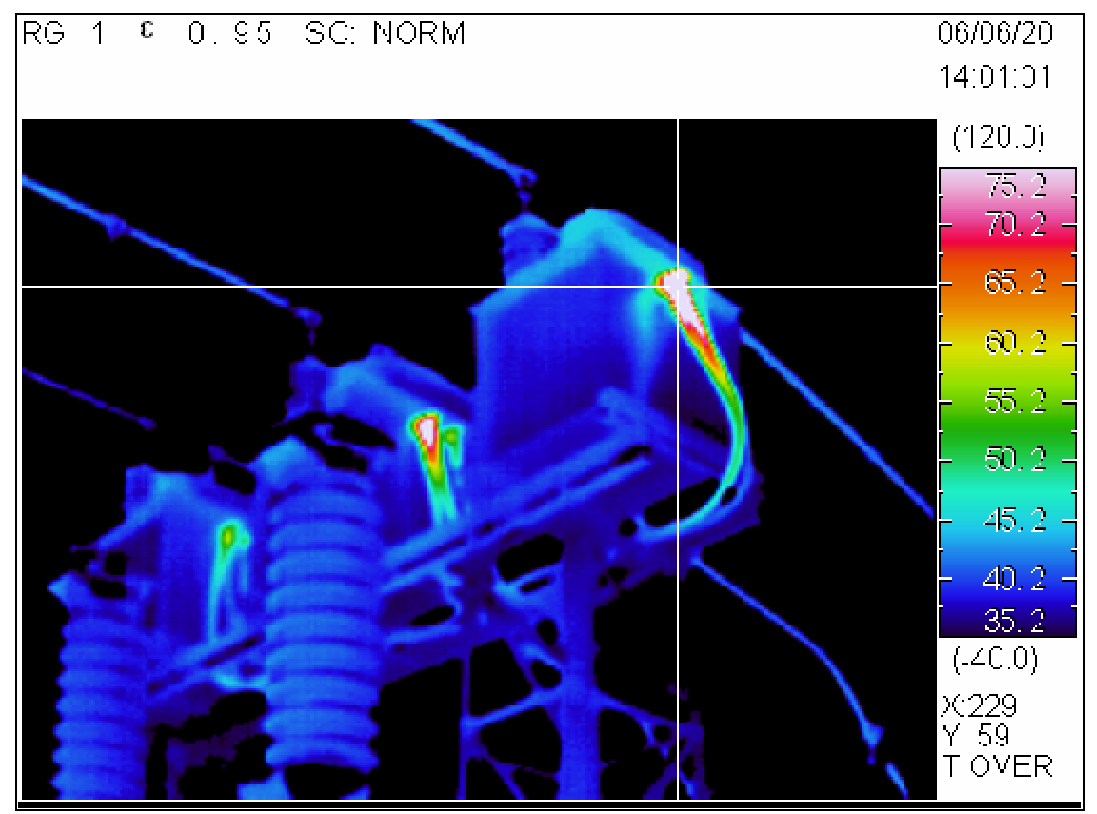

Fig. 2. Thermal image of infusion current transformers

As shown in the figure, the malfunctioning feeding cable exhibited at its joint with the transformer a temperature of about $120^{\circ} \mathrm{C}$, whereas the respective temperature of the rest of the installation was less than $50^{\circ} \mathrm{C}$, as would normally be expected. Further analysis of the incident indicated that the joint between the feeding cable and the transformer was made for aluminium cables, whereas the feeding cable itself was made of copper. Evidently the aluminium joint was overheated during its operation, the result being the destruction of the cable.

The scope of this paper is the thorough study of the incident. In this context, the theoretical background is provided for the process that led to the destruction of the joint. Moreover, an experimental setup was used for the study of the incident. More specifically, a copper cable with an aluminium termination was used to feed a number of appliances. The cable was loaded beyond its nominal thermal current limitations, and the process was recorded by the use of infrared thermography until the destruction of the copper-aluminium joint. Finally, the cable termination was post processed for the obtainment of information about the electro-chemical process that led to its destruction.

\section{Theoretical Background}

\section{The electromotive force series}

The electromotive force series (emf series) is widely used to classify various metals according to their potential versus a normal hydrogen electrode within pure water at $25^{\circ} \mathrm{C}$ (Table 1). Among other things, the emf series offers an indication concerning the effects of the galvanic connection of two different metals. In such a case, the metal more active in the emf series will comprise the anode and the one more noble will comprise the cathode in the resulting corrosive effect. As can be observed in Table 1, in the case of a galvanic connection between Copper $(\mathrm{Cu})$ and Aluminium $(\mathrm{Al})$, the resulting potential difference will reach $2 \mathrm{~V}$, whereas Aluminium will comprise the anode and Copper the cathode. Furthermore, if a joint of this type is connected to a voltage source, the current flowing through the joint in addition to the potential difference between the two metals will cause electrolysis, which in turn will result in the corrosion of the joint. This corrosion will appear at first in the forming of copper and aluminium oxides on the surface of the joint, which will lead to the increase of the joint's electrical resistance and temperature respectively. Subsequently, under specific conditions intermetallic compounds (IMC) will form, which will extend on the surface between the two metals causing ultimately the distraction of the joint.

\section{Intermetallic Compounds}

Much research has been conducted concerning the development of intermetallic compounds in joints between copper wires and aluminium contact pads in bonded interconnections in microelectronics [1] - [4]. The studies refer to the results concerning the annealing of $\mathrm{Al} / \mathrm{Cu}$ joints, which they implement as a means for accelerating the aging procedure of the joints. All results show the development of IMC on the surface between the two metals, $\mathrm{Cu}_{3} \mathrm{Al}, \mathrm{Cu}_{4} \mathrm{Al}_{3}, \mathrm{CuAl}$ and $\mathrm{CuAl}_{2}$ being the main IMC products (Fig. 3). During the aging process, an IMC film develops from the periphery of the joint and propagates inward towards the centre area. Subsequently, with increased aging time, cavities are observed to develop between the IMC layer and the $\mathrm{Cu}$ surface, also starting at the joint periphery [1]. 
Table 1. The emf series of pure metals within pure water

\begin{tabular}{|c|c|c|}
\hline & $\begin{array}{l}\text { Metal - metal ion } \\
\text { equilibrium (unit } \\
\text { activity) }\end{array}$ & $\begin{array}{l}\text { Electrode potential } \\
\text { vs. normal } \\
\text { hydrogen electrode } \\
\text { at } 25^{\circ} \mathrm{C} \text {, Volts } \\
\end{array}$ \\
\hline \multirow[t]{2}{*}{$\hat{\top}$} & $A u=A u^{3+}+3 e$ & +1.498 \\
\hline & $\mathrm{O}_{2}+4 \mathrm{H}^{+}+4 \mathrm{e}=2 \mathrm{H}_{2} \mathrm{O}$ & +1.229 \\
\hline \multirow{16}{*}{$\begin{array}{l}\text { Noble or } \\
\text { cathodic }\end{array}$} & $\mathrm{Pt}=\mathrm{Pt}^{2+}+2 \mathrm{e}$ & +1.2 \\
\hline & $\mathrm{Pd}=\mathrm{Pd}^{2+}+2 \mathrm{e}$ & +0.987 \\
\hline & $\mathrm{Ag}=\mathrm{Ag}^{+}+\mathrm{e}$ & +0.799 \\
\hline & $2 \mathrm{Hg}=\mathrm{Hg}_{2}^{2+}+2 \mathrm{e}$ & +0.788 \\
\hline & $\mathrm{Fe}^{3+}+\mathrm{e}=\mathrm{Fe}^{2+}$ & +0.771 \\
\hline & $\mathrm{O}_{2}+2 \mathrm{H}_{2} \mathrm{O}+4 \mathrm{e}=4 \mathrm{OH}$ & +0.401 \\
\hline & $\mathrm{Cu}=\mathrm{Cu}^{2+}+2 \mathrm{e}$ & +0.337 \\
\hline & $\mathrm{Sn}^{4+}+2 \mathrm{e}=\mathrm{Sn}^{2+}$ & +0.15 \\
\hline & $2 \mathrm{H}^{+}+2 \mathrm{e}=\mathrm{H}_{2}$ & 0.000 \\
\hline & $\mathrm{Pb}=\mathrm{Pb}^{2+}+2 \mathrm{e}$ & -0.126 \\
\hline & $\mathrm{Sn}=\mathrm{Sn}^{2+}+2 \mathrm{e}$ & -0.136 \\
\hline & $\mathrm{Ni}=\mathrm{Ni}^{2+}+2 \mathrm{e}$ & -0.250 \\
\hline & $\mathrm{Co}=\mathrm{Co}^{2+}+2 \mathrm{e}$ & -0.277 \\
\hline & $\mathrm{Cd}=\mathrm{Cd}^{2+}+2 \mathrm{e}$ & -0.403 \\
\hline & $\mathrm{Fe}=\mathrm{Fe}^{2+}+2 \mathrm{e}$ & -0.440 \\
\hline & $\mathrm{Cr}=\mathrm{Cr}^{3+}+3 e$ & -0.744 \\
\hline \multirow{5}{*}{$\begin{array}{l}\text { Active or } \\
\text { anodic }\end{array}$} & $Z n=Z n^{2+}+2 e$ & -0.763 \\
\hline & $\mathrm{Al}=\mathrm{Al} \mathrm{l}^{3+}+3 \mathrm{e}$ & -1.662 \\
\hline & $M g=M^{2+}+2 e$ & -2.363 \\
\hline & $\mathrm{Na}=\mathrm{Na}^{+}+\mathrm{e}$ & -2.714 \\
\hline & $\mathrm{K}=\mathrm{K}^{+}+\mathrm{e}$ & -2.925 \\
\hline
\end{tabular}

The development of IMC however can seriously impair the overall electrical stability and mechanical properties of bimetallic joints. The increased thickness of the IMC layer will produce a higher electrical resistance, leading to a higher heat generation in the case of current flowing through the joint [1]. Moreover, significant IMC growth can make the joint interface brittle, impairing thus its mechanical properties and leading to a potential mechanical failure.

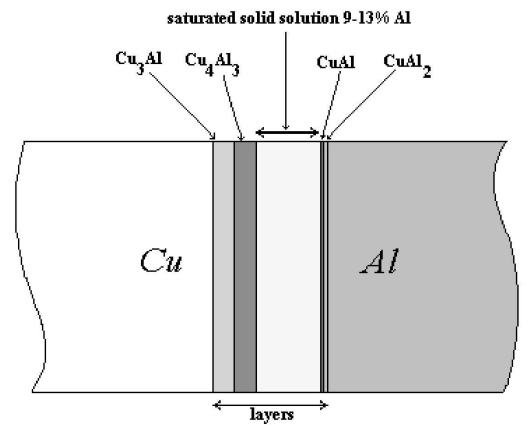

Fig. 3. Schematic diagram of the IMC produced in an Al/Cu joint

\section{Experimental setup}

\section{Experimental configuration}

The intention of the experimental setup was to monitor and record the process that leads to the destruction of a Cu/Al joint due to excessive overheating caused by electrolysis. For that purpose, a $1.5 \mathrm{~mm}^{2} \mathrm{single}^{-}$ conductor, single-core copper cable (NYA $1.5 \mathrm{~mm}^{2}$ per VDE 0250) was used to feed a number of low voltage $(230 \mathrm{~V})$ appliances with a total required power of $8 \mathrm{~kW}$ through a connection with an aluminium joint. The specific required power was selected to impose to the feeding cable a current higher than its rated load, so as to increase 
the temperature at the joint and accelerate thus the procedure. According to the CENELEC HD384.5.523 standard, the maximum permissible operational temperature of low voltage electrical equipment is $70^{\circ} \mathrm{C}$. To prevent the temperature rise due to the overloading of the cable reach the feeding low voltage panel, which would accordingly set off its protection measures, a $5 \mathrm{~m}$ long NYA $6 \mathrm{~mm}^{2}$ copper cable was used as an intermediate connection between the feeding panel and the NYA $1.5 \mathrm{~mm}^{2}$ cable under study. The connection between the NYA $6 \mathrm{~mm}^{2}$ and NYA $1.5 \mathrm{~mm}^{2}$ cable was selected as the testing point, therefore the respective joint was the one made from aluminium (Fig. 4). On its other end, the NYA $1.5 \mathrm{~mm}^{2}$ cable was connected to the rest of the experimental setup via a copper joint, so as to monitor the behaviour of the different joints.

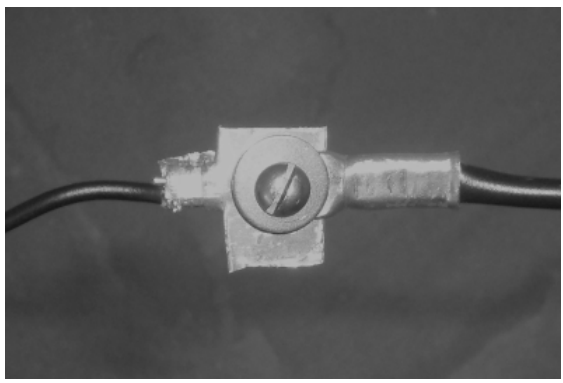

Fig. 4. Connection between copper cable and aluminium joint before the experiment

The configuration was powered, feeding the intermetallic joint with a current of about $35 \mathrm{~A}$ (well above the nominal rating of the NYA $1.5 \mathrm{~mm}^{2}$ cable), and a Fluke Ti 35 Thermal Imager was used to observe the outcome of the experiment. After two days of experiment, the feeding cable blew as expected at the point of the intermetallic joint due to local excessive heating (Fig. 5).

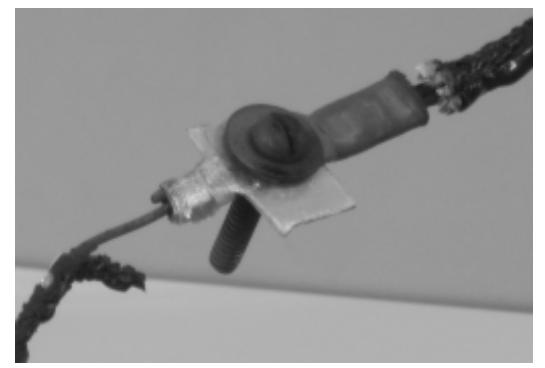

Fig. 5. Connection between copper cable and aluminium joint only minutes before the joint destruction

\section{Thermal Imaging Results}

The experimental setup was continuously monitored with the help of the infrared camera. The progress of the experiment can be observed in Fig. 6a-d.

As can be seen in Fig. 6a-b, the joint maximum temperature increased until it exceeded the camera sensitivity, whereas for the rest of the experiment a constant rise in the joint average temperature can be observed (Fig. 6b-c) until the joint destruction. Fig. $6 \mathrm{~d}$ depicts the thermal image of the joint moments after the joint failure.

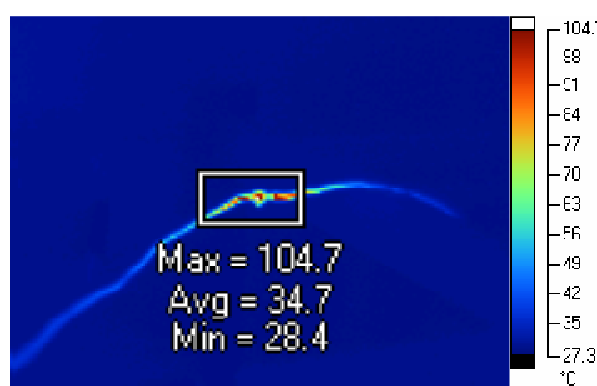

a)

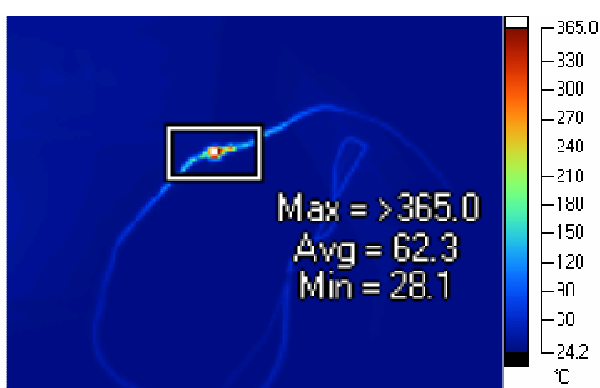

b) 


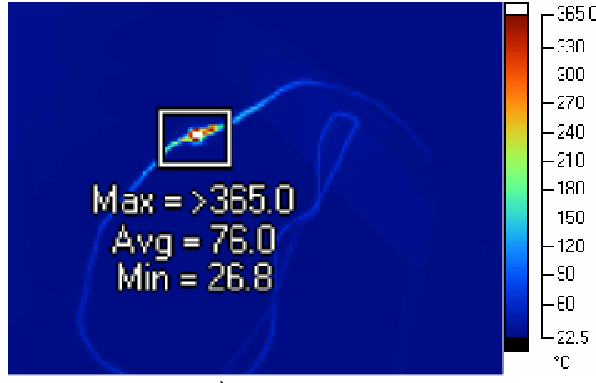

c)

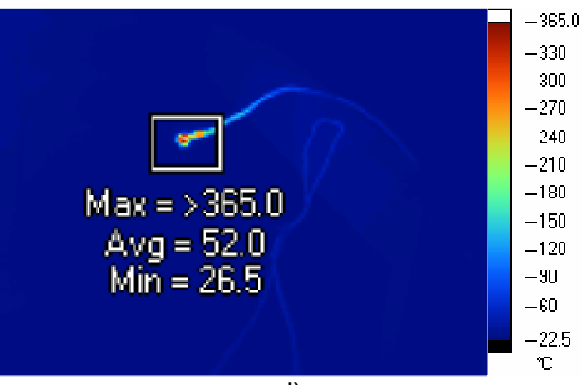

d)

Fig. 6. Thermal representation of the experiment progress

\section{Microscopic Analysis}

After the joint failure, the joint was disassembled and studied with the help of an electronic microscope. For this purpose, several samples were created that corresponded to different areas of the joint as shown in Fig. 7.

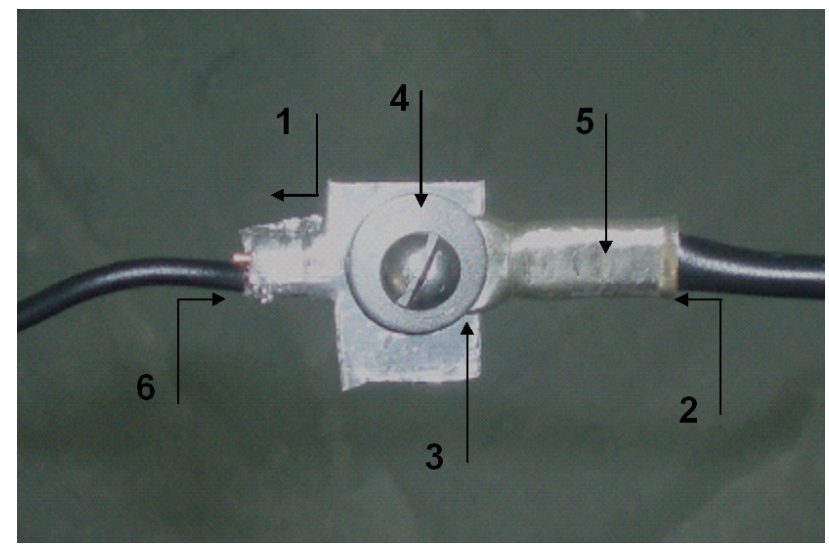

Fig. 7. Sample areas of joint for the microscopic analysis

Some indicative results of the microscopic analysis are presented in Figs. 8-10.

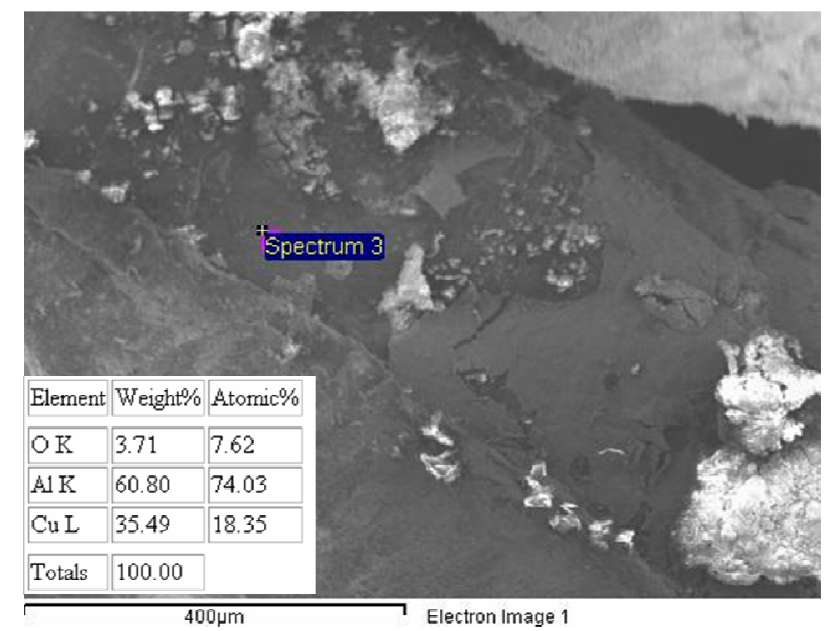

Fig. 8. Results of the microscopic analysis concerning sample area 1 


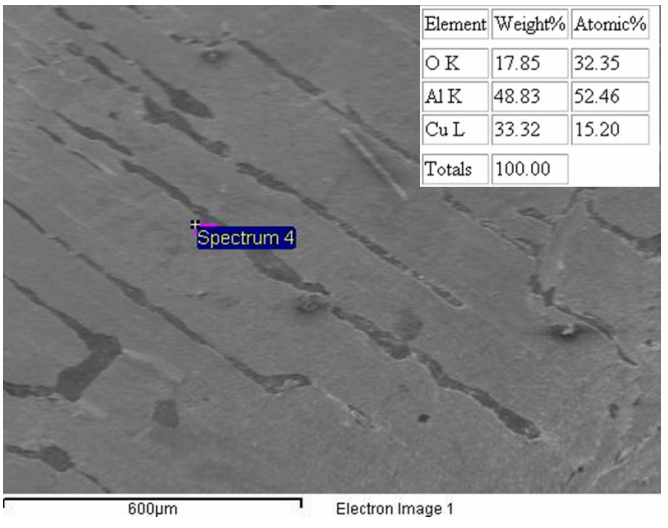

Fig. 9. Results of the microscopic analysis concerning sample area 3

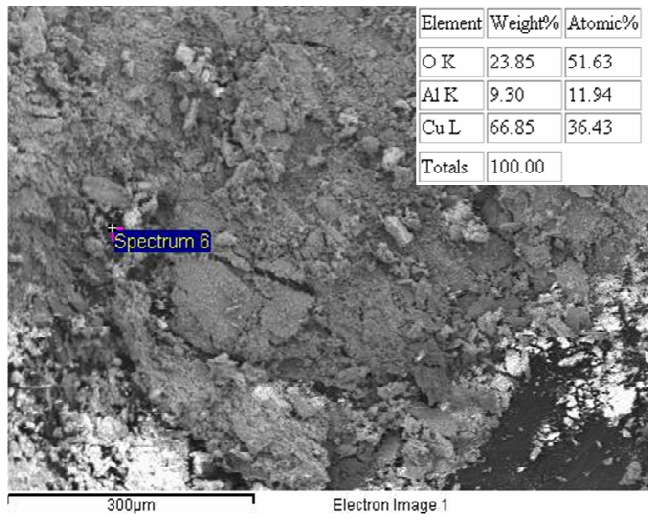

Fig. 10. Results of the microscopic analysis concerning sample area 6

The composition of the samples analyzed by the electronic microscope included basically $\mathrm{Cu}$ and $\mathrm{Al}$ oxides, whereas some points studied indicated the presence of IMC. However, the experiment results show that the growth of the oxides on the $\mathrm{Cu} / \mathrm{Al}$ joint surface along with the respective increase in the joint electrical resistance and temperature was sufficient for the joint destruction, whereas IMC development did not appear to influence the experiment outcome significantly. This suggestion is also supported by the fact that the joint destruction did not occur due to a mechanical failure that would suggest IMC development, but only due to excessive temperature rise of the joint.

\section{Conclusion}

The scope of this paper was to analyze the reasons that led to the destruction of a Cu/Al joint of a cable feeding a Ripple Control Transformer. For that purpose, a theoretical explanation of the phenomenon was presented. The actual phenomenon was subsequently reproduced using an experimental setup. The results obtained by this setup were indicative of the reason for the joint destruction at the Ripple Control Transformer, namely the formation of metallic oxides on the surface between the copper cable and the aluminium joint. These metallic oxides were the result of electrolysis, and their growth led to a local increase of the joint electrical resistance, resulting therefore in an excessive temperature rise that led ultimately to the joint destruction. After its destruction, the $\mathrm{Cu} / \mathrm{Al}$ joint of the experimental setup was subjected to microscopic analysis. The results of the analysis showed excessive metallic oxides development, without a respective IMC growth, supporting thus the aforementioned suggestion.

\section{Acknowledgments}

The authors would like to thank Mr. Lazaros loannidis and Mr. Anastasios Satanakis for the information they provided on behalf of the PPC concerning the fault at the Ripple Control infusion current trasformer. Moreover, they would also like to express their gratitude towards $\mathrm{Dr}$. H. Omar for his help with the electronic microscope.

\section{REFERENCES}

[1] C.J. Hang, C.Q. Wang, M. Mayer, Y.H. Tian, Y. Zhou and H.H. Wang. Growth behavior of Cu/Al intermetallic compounds and cracks in copper ball bonds during isothermal aging, Microelectronics Reliability, 48 (2008) 416-424.

[2] Hyoung-Joon Kim, Joo Yeon Lee, Kyung-Wook Paik, Kwang-Won Koh, Jinhee Won, Sihyun Choe, Jin Lee, Jung-Tak Moon, and Yong-Jin Park. Effects of Cu/Al Intermetallic Compound (IMC) on Copper Wire and Aluminum Pad Bondability, IEEE Trans on Components and Packaging Technologies, Vol. 26, No. 2, June 2003.

[3] Won-Bae Lee, Kuek-Saeng Bang, Seung-Boo Jung. Effects of intermetallic compound on the electrical and mechanical properties of friction welded $\mathrm{Cu} / \mathrm{Al}$ bimetallic joints during annealing, Journal of Alloys and Compounds 390 (2005) 212-219.

[4] M. Abbasi, A. Karimi Taheri, M.T. Salehi. Growth rate of intermetallic compounds in Al/Cu bimetal produced by cold roll welding process, Journal of Alloys and Compounds 319 (2001) 233-241. 